\title{
Properties of the 2003 Lefkada, Ionian Islands, Greece, Earthquake Seismic Sequence and Seismicity Triggering
}

\author{
by Vassilis G. Karakostas, Eleftheria E. Papadimitriou, and Costas B. Papazachos
}

\begin{abstract}
On 14 August 2003, Lefkada Island (Central Ionian) was strongly affected by an $M_{\mathrm{w}}=6.2$ earthquake. A dense temporary seismic network was installed one day after and accurately located hundreds of aftershocks that defined in detail the main rupture, as well as the activity distribution in the neighboring fault segments. The main rupture occupied the northwestern part of the coastline and trends northnortheast-south-southwest in agreement with regional tectonics. Regional network locations were appropriately calibrated using the local network data, allowing the relocation of the mainshock and strong ( $M \sim 4.5$ or larger) aftershocks during the first day. Intense aftershock activity took place up to $40 \mathrm{~km}$ beyond the southern end of the main rupture. Theoretical static stress changes from the mainshock give a preliminary explanation for the aftershock distribution aside from the main rupture, as well as triggering of seismicity in the nearby Kefalonia fault, providing evidence for future seismic hazard ensuing from this fault.
\end{abstract}

\section{Introduction}

An $M_{\mathrm{w}} 6.2$ earthquake occurred on 14 August 2003 (05:14 UTC) on Lefkada Island. Lefkada, along with the nearby Kefalonia Islands, constitutes the most active part of shallow seismicity in the broader Aegean region (Fig. 1). Seismicity is associated with dextral strike-slip faulting along the Cephalonia Transform Fault (CTF in Fig. 1) comprising the distinctive Kefalonia and Lefkada faults (Scordilis et al., 1985; Louvari et al., 1999; Papazachos et al., 2001). The study area is located between the continental collision of the Outer Hellenides and the Adriatic microplate to the north and the oceanic subduction of the eastern Mediterranean lithosphere under the Aegean Sea to the south (Papazachos and Comninakis, 1971).

Lefkada Island has suffered several times from strong seismic excitations causing collapse of buildings, injuries, and even loss of life (Papazachos and Papazachou, 2002). Adequate historical information reveals the frequent occurrence of strong $(M \geq 6.0)$ events, causing the most severe damage along the western part of the island and confirming their association with a fault running along the western coast. In addition to the moderate magnitude earthquakes that affect this area, the last events of $M \geq 6.0$ took place on 22 April 1948 (M 6.5) in the southern part of the island and two months later, on 30 June 1948, a second one ( $M$ 6.4) in its northern part. It is worth mentioning that the recurrence period of the activated fault segment is of the order of few decades since in 1914, an $M 6.3$ event occurred there, and during the preinstrumental era, the macroseismic effects of the $1869(M \sim 6.4)$ earthquake also revealed the activation of this fault segment.

An additional major threat to Lefkada Island arises from the even more frequent earthquakes that occur in nearby Kefalonia Island and in particular in its northern part or in the sea area between the two islands. In 1915, when two strong events on 27 January ( $M$ 6.6) and 7 August ( $M$ 6.7) occurred in Kefalonia Island, severe damage was reported in the urban areas of southern Lefkada. In 1953, three strong events $(M$ 6.4, 7.2, and 6.3) that occurred in Kefalonia and Ithaki Islands also had catastrophic consequences in Lefkada. It is noteworthy that in both cases the buildings in Lefkada were strained by the preceding 1914 and 1948 earthquakes. Earthquake triggering by stress transfer between the Lefkada and Kefalonia faults has been suggested as a probable pattern for strong earthquake occurrence in the area (Papadimitriou, 2002). The evolved stress field that was calculated up to 2002 revealed that the location of the 2003 mainshock is inside a stress enhanced area.

The aim of this study is to define in detail the properties of the fault associated with the 14 August 2003 mainshock and to identify contemporaneously activated neighboring fault segments. In addition, an assessment of the possible future hazard derived from the activation of the neighboring faults that pose a major threat to the study area is made by examining how the mainshock occurrence affected the stress field, since it is well accepted that even small static stress changes due to coseismic displacement can trigger earth- 


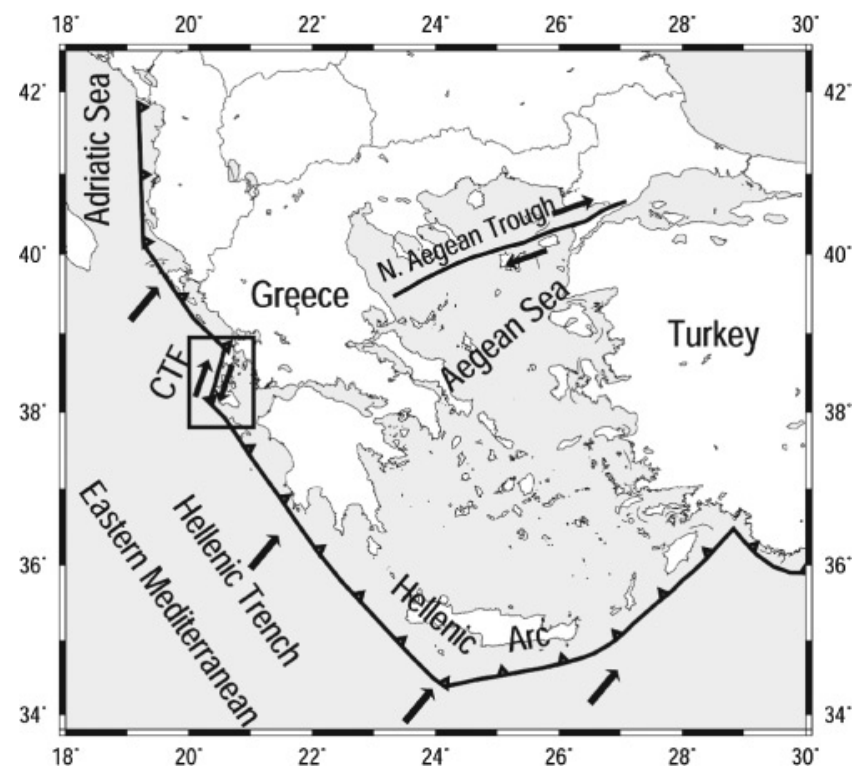

Figure 1. Main seismotectonic properties of the Aegean and surrounding regions. The study area is indicated by a rectangle. CTF $=$ Cephalonia Transform Fault.

quakes on nearby faults (Harris, 1998, and references therein).

\section{Aftershock Distribution}

One day after the main shock, a portable seismic network was deployed in the area consisting of seven threecomponent stations equipped with five broadband (30 sec) and two short-period $(1 \mathrm{~Hz})$ sensors. The spacing between stations varied from 5 to $10 \mathrm{~km}$, allowing accurate location of the aftershocks. The recordings of the local network were enriched with those from the stations of the regional seismological network and in particular from a permanent analog seismological station, maintained by the Geophysics Department of Thessaloniki University, which is in continuous operation (Fig. 2). $P$ and $S$ phases have been picked for more than 1000 events that occurred between 15 August, 18:16 and 21 August and earthquakes were located using the velocity model proposed for the study area by Haslinger et al. (1999). In Figure 2, the locations of 751 events are shown, recorded at four stations or more (a minimum of eight phases), having an rms error of less than $0.2 \mathrm{sec}$, a horizontal location error of less than $2.0 \mathrm{~km}$, and a depth error of less than $2.0 \mathrm{~km}$; the corresponding median errors is $\sim 1 \mathrm{~km}$ for both horizontal and depth estimates.

The epicentral distribution of Figure 2 suggests that the activity is concentrated along the western coast of Lefkada Island, and important contemporaneous activity is also observed in the sea area between Lefkada and Kefalonia Islands. Most of the aftershocks are clustered on the northwestern part (cluster $\mathrm{AB}$ in Fig. 2), defining a north-northeast-south-southwest seismic band, which is in

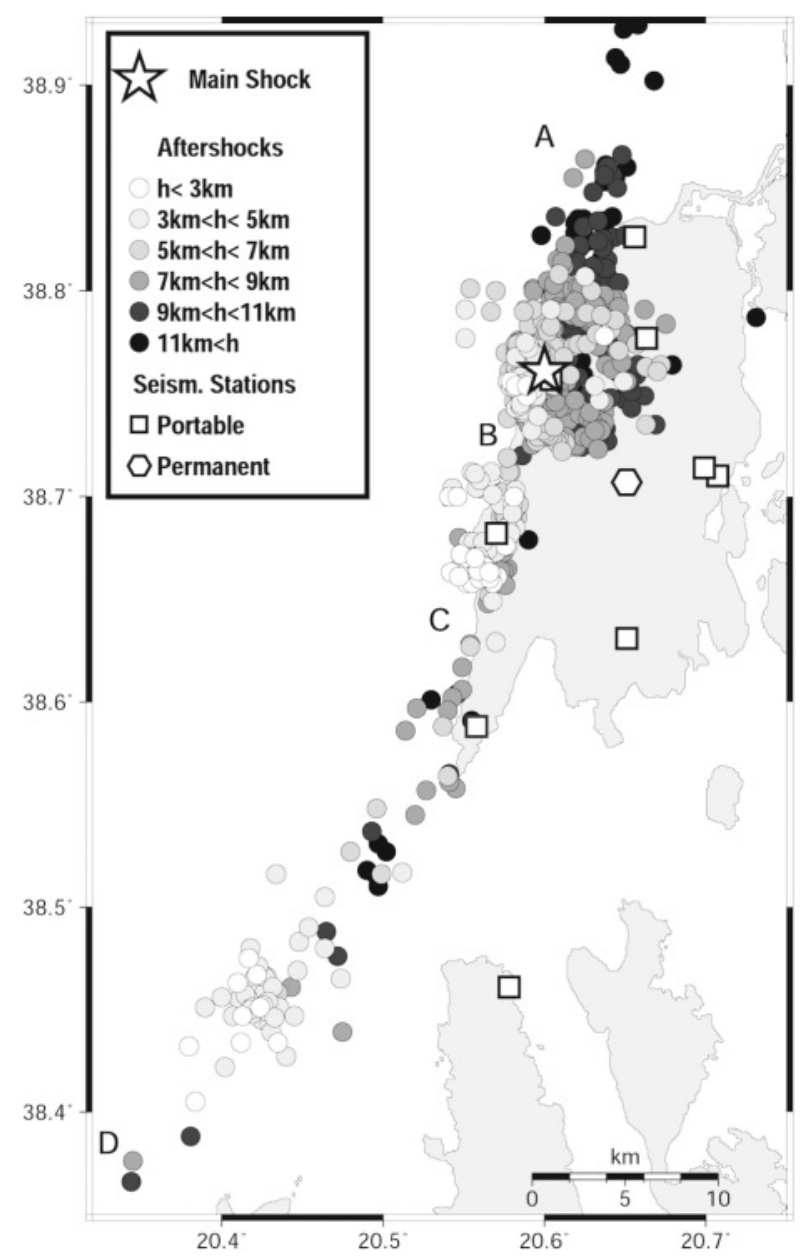

Figure 2. Epicentral map of the Lefkada aftershock sequence. Squares indicate the stations of the temporary network, and the polygon denotes the permanent station position.

agreement with the strike of one of the mainshock nodal planes, according to the CMT solution determined by Harvard (strike $=18^{\circ}, \operatorname{dip}=60^{\circ}$, slip $=-175^{\circ}$, which is considered the fault plane. The relocated epicenter of the mainshock (following a procedure discussed later) is located at the southern part of this cluster that is considered the main rupture volume. The strike length of this cluster equals 16 $\mathrm{km}$ that is in good agreement with the fault length corresponding to an $M 6.2$ earthquake (20.5 and $18.5 \mathrm{~km}$ according to scaling laws suggested by Papazachos [1989] and Wells and Coppersmith [1994], respectively).

A smaller distinctive cluster appears south of the main aftershock cluster, well separated by an area that is free of epicenters (cluster BC in Fig. 2). It is interesting to note here that significant damage in buildings along with landslides and rock falls was also observed in the area defined by these two clusters. It is difficult to decide whether the aftershockfree area is locked or has completely slipped during the mainshock; if this cluster were included in the main rupture, then the fault length increases from 16 to $23 \mathrm{~km}$. The after- 


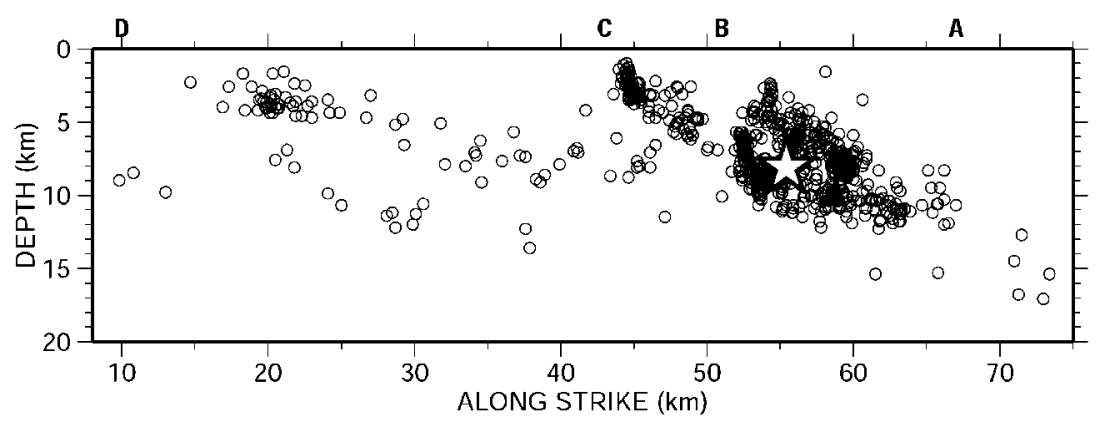

Figure 3. Fault-plane view of the Lefkada sequence. The mainshock is denoted by a star, and circles denote the aftershocks located by the local network.

shock distribution (Fig. 2) and the along-strike section (Fig. 3) show that the cluster $B C$ is much shallower than the aftershock activity of the northern cluster, hence could be attributed to the activation of a neighboring fault segment. However, additional information concerning the slip distribution along the fault needs to be obtained for complete clarification of this issue.

An additional alignment of seismicity is identified between Lefkada and Kefalonia Islands (from $38.4^{\circ}$ up to $38.6^{\circ}$, cluster $\mathrm{CD}$ in Fig. 2) with a trend in excellent agreement with the strike of $28^{\circ}$ of the fault plane solution of a moderate event $\left(M_{\mathrm{w}} 5.4\right)$ that occurred on 14 May 1983 (Harvard CMT solution). Evidence of the triggering of this activity as well as of the cluster next to the main rupture (cluster BC) is provided in a latter section where Coulomb stress changes associated with the mainshock occurrence are resolved.

An effort is made to relocate the mainshock and strong aftershocks that occurred within the first 35 hours after the mainshock, before the local network was in full operation. Using the local network's accurate hypocentral locations, the stronger aftershocks ( $M \sim 4.5$ or larger) that were recorded by both the local and regional networks were used to calibrate the regional network of the Geophysics Department of the University of Thessaloniki by computing appropriate station corrections for the reference velocity model. We first consider the events that were recorded by both the regional and local network, and assuming the focal determinations by the local recordings alone are accurate, we estimated corrections for the stations of the regional network. Figure 4 shows the local network locations of these strong aftershocks (solid circles) and the corresponding regional network determination (open circles) after adding the station corrections. Although the regional determinations show a much more diffuse epicentral distribution, they are aligned close and along the Lefkada and Kefalonia faults, providing evidence that this procedure enables an adequately precise location by the regional recordings alone. For the mainshock location, additional $S$ - $P$ travel times were used from the nearest strong-motion instruments operated by ITSAK in the cities of Lefkada and Preveza (shown in Fig. 4) that contributed to locating it more accurately.

The epicenters of the mainshock and the stronger aftershocks until 21 August 2003 are shown in Figure 5, which

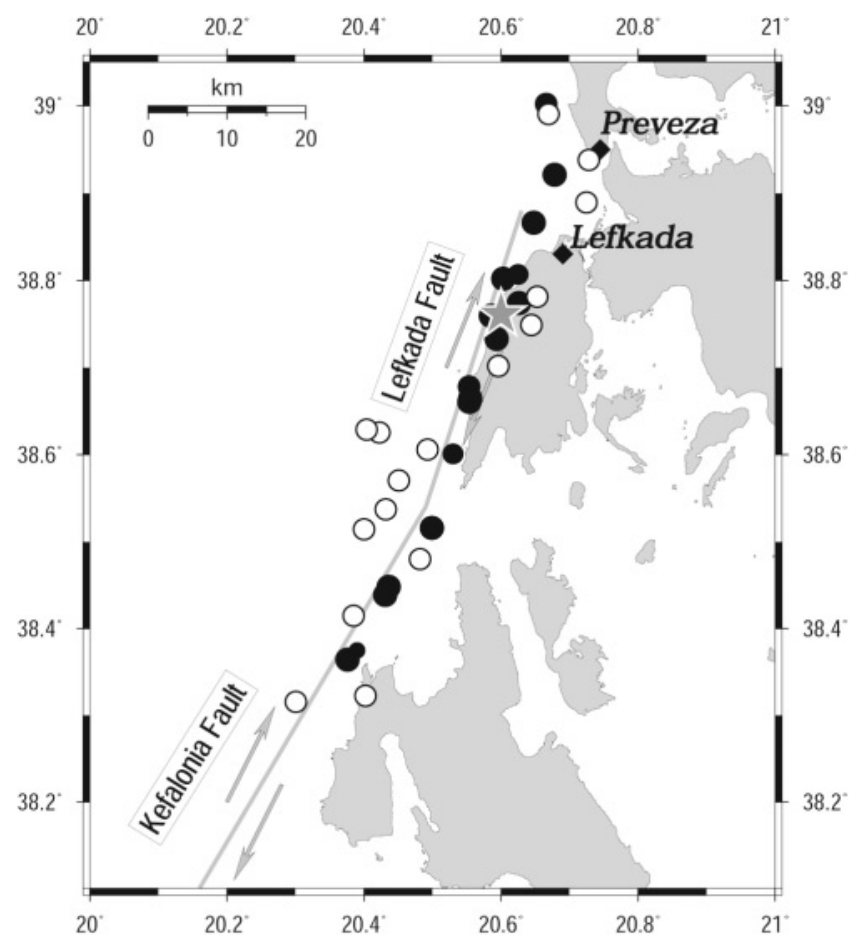

Figure 4. Spatial distribution of the strong aftershocks used to calibrate the regional network (solid circles) and corresponding regional determinations (open circles). Diamonds denote the locations of the cities of Lefkada and Preveza. The general geometries of the Lefkada and Kefalonia faults are also presented.

reveals that the activity during the first 15 hours after the mainshock was confined to the northern and central part of the Lefkada fault (solid circles in Fig. 5). After that time, the seismic activity continued there and also expanded southward and occupied the southern part of the Lefkada and the northern part of Kefalonia faults (open circles in Fig. 5).

\section{Coseismic Coulomb Stress Changes and Triggering of Seismicity in Nearby Fault Segments}

The aftershock distribution (Figs. 2 and 3) suggests that the main rupture is well approximated by a planar fault $16 \mathrm{~km}$ long and extending from 3 to $12 \mathrm{~km}$ in depth. From 


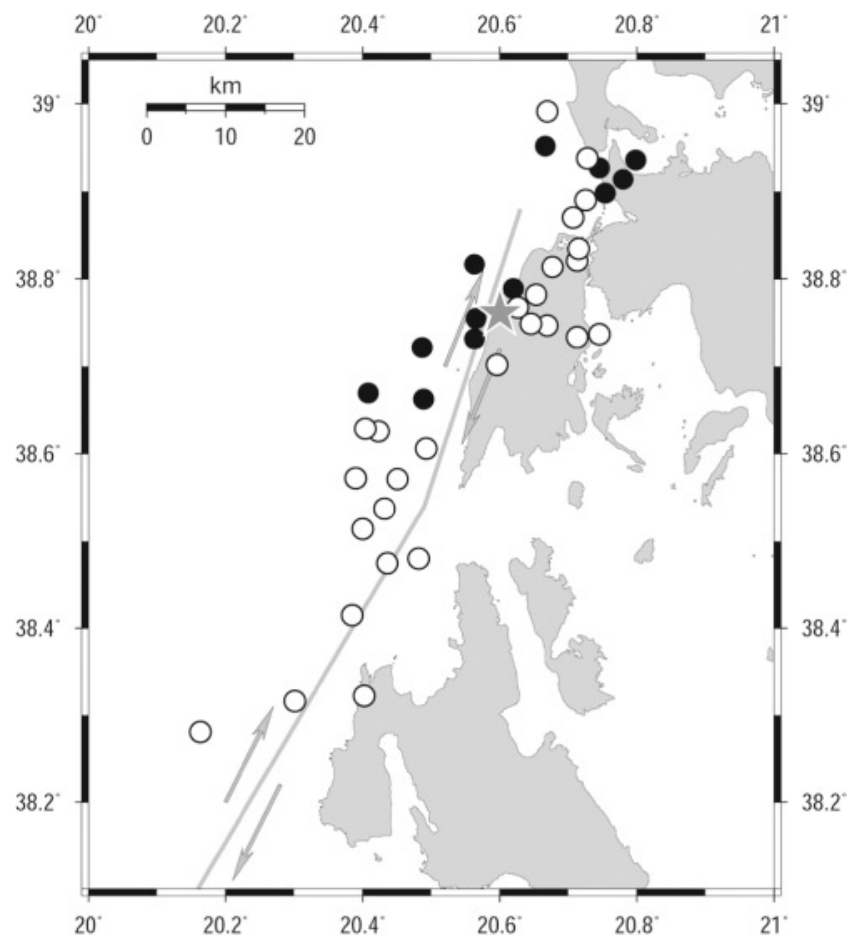

Figure 5. Mainshock (14 August 2003, 05:14, $M$ 6.2) depicted by a star and stronger aftershock spatial distribution, as determined from regional network relocations. Solid circles represent the aftershocks until 14 August 2003, 20:30, and the open circles the aftershocks that occurred after that time and until 21 August 2003.

the dimensions of the fault segment associated with the mainshock and a seismic moment equal to $2.9 \times 10^{25}$ dyne $\mathrm{cm}$ (Harvard CMT solution), a mean slip of $\sim 60 \mathrm{~cm}$ was computed. It is expected that the mainshock affected the aftershock activity along the adjacent fault segment on Lefkada Island, as well as on the northern part of the Kefalonia fault, as has been noticed in several cases (Reasenberg and Simpson, 1992; Stein et al., 1994; Harris, 1998; Stein, 1999). Stress changes, that is, values of $\triangle C F F$ (changes in Coulomb failure function), caused by the mainshock are computed for a dextral strike-slip fault in agreement with the fault-plane solution of the May 1983 event (strike $=28^{\circ}$, $\operatorname{dip}=82^{\circ}$, rake $=172^{\circ}$ ) at a depth of $8 \mathrm{~km}$. The stress calculations are performed for an isotropic elastic half-space (Erikson, 1986; Okada, 1992; Simpson and Reasenberg, 1994). The closeness to failure is quantified using the change in the Coulomb failure function:

$$
\Delta \mathrm{CFF}=\Delta \tau+\mu^{\prime} \Delta p,
$$

where $\Delta \tau$ is the shear stress change (computed in the slip direction), $\Delta \sigma$ is the fault-normal stress change (positive for extension), and $\mu^{\prime}$ is the friction apparent coefficient that is taken equal 0.6 in the calculations, a value suggested as ap- propriate for aftershock areas (Harris, 1998; Karakostas et al., 2003). Higher values could be used as well, since the pore pressure is lowered after the mainshock occurrence, in accordance with laboratory experiments for dry rock samples (Byerlee, 1978). The stress pattern remained unaltered when the calculations were performed at different depths ( $\mathrm{h}=10$ and $12 \mathrm{~km}$ ) or when values of 0.2 and 0.4 were used for the $\mu^{\prime}$ parameter. The results are presented in Figure 6 , where the off-fault activity is seated inside the southern lobe of positive $\triangle \mathrm{CFF}$ values. Lack of significant seismic activity inside the other three lobes can be attributed to the fact that only the southern lobe is along the main dextral strike-slip zone (Fig. 1), along the strike with the Lefkada mainshock. If the activity of the southern lobe would culminate with a main event, its magnitude could be larger than 6.0 , since the along-strike dimension of this alignment corresponds to a fault capable of producing such an event. In addition to low magnitude earthquake activity, a moderate magnitude earthquake ( $M 5.1$ ) occurred there on 16 November 2003, evidence of the stress enhancement.

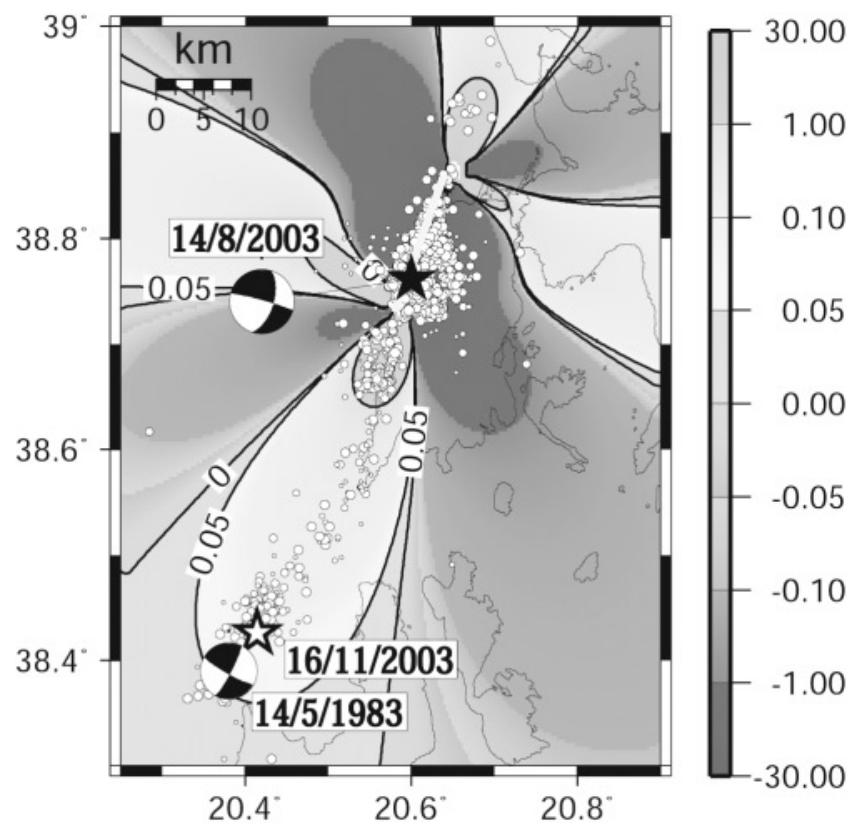

Figure 6. Static Coulomb stress changes (in bars), due to the Lefkada mainshock (solid star) at a depth of $8 \mathrm{~km}$ with $\mu^{\prime}=0.6$ for a representative fault-plane solution along the northern Kefalonia fault (strike = $28^{\circ}$, dip $=82^{\circ}$, and rake $=172^{\circ}$ ). Contours denote values of $0,0.05$, and 1 bar. The thick white line depicts the dimensions of the main rupture. Aftershock activity (small circles) not related to the main rupture is concentrated exclusively in areas of positive static stress changes. Two clusters of aftershocks, south and north of the main rupture, are distributed in areas with stress changes higher than 1 bar. The epicenter of 16 November 2003 (open star) and the fault-plane solution of the 14 May 1983 earthquake are also shown. 


\section{Discussion and Conclusions}

The properties of the Lefkada Island seismic sequence were studied using a data set of accurately estimated aftershock hypocenters from the operation of a dense temporary network in the aftershock area. Although the Lefkada fault was known as to be associated with strong $(M \geq 6.0)$ earthquake occurrence, its geometry was not detailed since it is the first time that accurately located aftershock hypocenters by a local digital network are available for this scope. The epicenter distribution defines an north-northeast-southsouthwest trending alignment along the western coast of the island, extending in the sea area toward the south. The mainshock occurred in the southern part of the main rupture, and the strongest aftershock (14 August, 16:18, M 5.4) occurred approximately at the other rupture end (Fig. 5), close to the city of Lefkada, where it was much more strongly felt than in the central and southern parts of Lefkada Island. The mainshock rupture was well determined, since it was constrained by gaps in seismic activity both at its northern and southern edges. It extended from 3 up to $12 \mathrm{~km}$ in depth, and its surface projection is in excellent agreement with the sea bottom morphology that runs parallel and very close to the steep coastline. The landslides and rock falls, particularly along the northwest coast, which took place contemporaneously with the mainshock occurrence, substantiate the fault position and the associated hazard. Dipping to the east, the activated fault constitutes a major threat to constructions, since the earthquake foci are located directly underneath the urban areas of the island.

The intense activity that was observed beyond the southernmost termination of the main rupture can be interpreted from the computed static stress changes associated with the mainshock. This activity is considerably shallower and is confined in narrow seismic bands that differ in strike (Figs. 2 and 3). A discernible shallow cluster (1-5 km) corresponds to the southern segment of the Lefkada fault (cluster BC in Fig. 2), which in 1948 slipped 2 months before the northern segment. The submarine seismic alignment between Lefkada and Kefalonia Islands (cluster CD in Fig. 2), $\sim 30 \mathrm{~km}$ long, exhibits a different strike slightly rotated to the east (by $\sim 10^{\circ}$ ) in accordance with the available faultplane solutions. The activity prolongation along this fault segment $\sim 15$ hours after the mainshock provides evidence for the triggering of this segment due to the static stress loading ensuing from the mainshock. The occurrence of the $M 5.1$ earthquake on 16 November, near the southern edge of this cluster (Fig. 6), is evidence of the static stress enhancement in this area.

\section{Acknowledgments}

This work was partially supported by the Local Union of Lefkada Island Municipalities. The stress tensors were calculated using a program written by Erikson (1986) and the expressions of G. Converse. The GMT system (Wessel and Smith, 1995) was used to plot the figures. The com- ments of an anonymous reviewer and the editorial assistance of Diane Doser are greatly appreciated. Department of Geophysics Contribution 635.

\section{References}

Byerlee, J. D. (1978). Friction of rocks, Pure Appl. Geophys. 116, 615626.

Erikson, L. (1986). User's manual for DIS3D: a three-dimensional dislocation program with applications to faulting in the Earth, Master's Thesis, Stanford University, Stanford, California, $167 \mathrm{pp}$.

Harris, R. (1998). Introduction to special section: stress triggers, stress shadows, and implications for seismic hazard, J. Geophys. Res. 103, $24,347-24,358$.

Haslinger, F., E. Kissling, J. Ansorge, D. Hatzfeld, E. Papadimitriou, V. Karakostas, K. Makropoulos, H.-G. Kahle, and Y. Peter (1999). 3D crustal structure from local earthquake tomography around the gulf of Arta (Ionian region, NW Greece), Tectonophysics 304, 201218.

Karakostas, V. G., E. E. Papadimitriou, G. F. Karakaisis, C. B. Papazachos, E. M. Scordilis, G. Vargemezis, and E. Aidona (2003). The 2001 Skyros, Northern Aegean, Greece, earthquake sequence: off-fault aftershocks, tectonic implications, and seismicity triggering, Geophys. Res. Lett. 30, no. 1, 1012, doi 10.1029/2002GL015814.

Louvari, E., A. A. Kiratzi, and B. C. Papazachos (1999). The Cephalonia Transform Fault and its extension to western Lefkada Island (Greece). Tectonophysics 308, 223-236.

Okada, Y. (1992). Internal deformation due to shear and tensile faults in a half-space, Bull. Seism. Soc. Am. 82, 1018-1040.

Papadimitriou, E. E. (2002). Mode of strong earthquake recurrence in central Ionian Islands (Greece). Possible triggering due to Coulomb stress changes generated by the occurrence of previous strong shocks, Bull. Seism. Soc. Am. 92, 3293-3308.

Papazachos, B. C. (1989). Measures of earthquake size in Greece and surrounding areas, in Proc. of the 1st Sci. Conf. of Geophysics, Geophys. Soc. of Greece, Athens, Greece, 19-21 April 1989, 438-447.

Papazachos, B. C., and P. E. Comninakis (1971). Geophysical and tectonic features of the Aegean Arc, J. Geophys. Res. 76, 8517-8533.

Papazachos, B. C., and C. Papazachou (2002). The Earthquakes of Greece, Ziti Publ., Thessaloniki, Greece, 317 pp.

Papazachos, B. C., D. M. Mountrakis, C. B. Papazachos, M. D. Tranos, G. F. Karakaisis, and A. S. Savvaidis (2001). The faults that caused the known strong earthquakes in Greece and surrounding areas during 5th century B.C. up to present, in Proc. 2nd Conf. Earthquake Eng. and Eng. Seism., 2-30 September 2001, Thessaloniki, Greece, 1, $17-26$.

Reasenberg, P. A., and R. W. Simpson (1992). Response of regional seismicity to the static stress change produced by the Loma Prieta earthquake, Science 255, 1687-1690.

Scordilis, E. M., G. F. Karakaisis, B. G. Karakostas, D. G. Panagiotopoulos, P. E. Comninakis, and B. C. Papazachos (1985). Evidence for transform faulting in the Ionian Sea: the Cephalonia Island earthquake sequence, Pure Appl. Geophys. 123, 388-397.

Simpson, R. W., and P. A. Reasenberg (1994). Earthquake-induced static stress changes on central California faults. In The Loma Prieta, California Earthquake of October 17, 1989-Tectonic processes and models, R. W. Simpson (Editor), U.S. Geol. Surv. Profess. Pap. 1550-F, F55-F89.

Stein, R. S. (1999). The role of stress transfer in earthquake occurrence, Nature 402, 605-609.

Stein, R. S., G. C. P. King, and J. Lin (1994). Stress triggering of the 1994 $M 6.7$ Northridge, California, earthquake by its predecessors, Science 265, 1432-1435.

Wells, D. L., and K. J. Coppersmith (1994). New empirical relationships among magnitude, rupture length, rupture width, rupture area, and surface displacement, Bull. Seism. Soc. Am. 84, 974-1002. 
Wessel, P., and W. H. F. Smith (1995). New version of the Generic Mapping Tools released, EOS, Trans. Am. Geophys. U. 76, 329.

Geophysics Department

University of Thessaloniki, GR54124

Thessaloniki, Greece

vkarak@geo.auth.gr

(V.G.K.)

ritsa@geo.auth.gr

(E.E.P.)

costas@geo.auth.gr

(C.B.P.)

Manuscript received 22 December 2003. 